\title{
Perfil socioeconômico dos produtores de queijo colonial gaúcho e a importância da produção artesanal
}

\author{
Bruna Bresolin Roldan* \\ Larissa Bueno Ambrosini** \\ Carolina Bremm**** \\ Denise Reif Kroeff $f^{* * *}$
}

\begin{abstract}
Resumo
O queijo colonial é muito apreciado pelos consumidores, sendo produzido basicamente com três ingredientes: leite, coalho e sal. Sua produção é realizada no ambiente familiar, para consumo doméstico ou para venda informal e por pequenas, médias e grandes empresas. Devido à importância econômica, social e cultural que esse produto possui, este estudo buscou analisar o perfil socioeconômico dos produtores de queijo colonial do estado do Rio Grande do Sul. Foi possível verificar que a idade avançada dos produtores, a experiência na produção, a origem da atividade nos imigrantes italianos, bem como circuitos curtos de comercialização e as relações de confiança entre produtores e consumidores, caracterizam a atividade de produção de queijo colonial como tradicional.
\end{abstract}

Palavras-chave: agroindústria familiar; agregação de valor; desenvolvimento rural.

* Doutora em Agronegócios/EMATER/RS-Ascar. E-mail: brunabre@gmail.com

** Doutora em Gestão/SEAPDR/RS. E-mail: larissabueno@gmail.com

**** Doutora em Zootecnia/SEAPDR/RS. E-mail: carolina.bremm@yahoo.com.br

***** Mestre em Sociologia/SEAPDR/RS. E-mail: denise.kroeff@gmail.com

http://dx.doi.org/10.5335/rtee.v26i55.12446

Submissão: 05/04/2021. Aceite: 29/04/2021. 


\section{Introdução}

O queijo colonial tem sua produção difundida por praticamente todo o território dos estados do Rio Grande do Sul, Santa Catarina e Paraná. Ele é produzido por pequenos produtores informais, agroindústrias familiares, médias e grandes empresas do setor lácteo (SILVEIRA; TREVISAN, 2007). Apesar disso, o produto não possui um regulamento técnico de identidade e qualidade que defina suas principais características.

Em que pese a falta de regulamentação, pode-se dizer que em geral o queijo colonial é produzido com leite cru ou pasteurizado, coalho e sal, sendo moldado em formas retangulares ou circulares, sendo comercializado com poucos dias de maturação (AMBROSINI et al., 2020; TAVARES et al., 2019). Assim como os demais queijos artesanais, suas características têm estreita relação com a qualidade de solos, matérias-primas, alimentação dos animais e práticas culturais consideradas tradicionais, fatores que os diferenciam dos produtos industriais (CHALITA, 2012; ZUMBO et al., 2009).

De acordo com dados do Relatório Socioeconômico da Cadeia Produtiva do Leite no RS (EMATER/RS-ASCAR, 2019), 7.690 produtores produzem derivados lácteos, dentre eles o queijo colonial, em agroindústrias próprias legalizadas (187) ou em instalações domésticas (7.503), o que demonstra o grande número de famílias envolvidas e a oportunidade para o fomento dessa produção (EMATER/RS-ASCAR, 2019).

O conhecimento a respeito do perfil socioeconômico dos produtores de queijo colonial se faz importante justamente para orientar políticas públicas, como as relacionadas à capacitação e ao fomento, incluindo o crédito e a assistência técnica, bem como a regulamentação da atividade. Além disso, a produção de leite e derivados nas pequenas propriedades é uma importante ferramenta no combate à pobreza, na geração de renda e no desenvolvimento do meio rural, além de contribuir para a segurança alimentar, a manutenção da paisagem rural e do patrimônio cultural (ESPINOZA-ORTEGA et al., 2007; FLATEN, 2002).

Os objetivos deste estudo são: i) analisar o perfil socioeconômico dos produtores de queijo colonial do estado do Rio Grande do Sul; ii) demonstrar a relevância da atividade como fonte de renda para as propriedades e as oportunidades geradas em termos de ocupação de mão de obra e atratividade para os jovens; e iii) demonstrar a necessidade de desenvolvimento de políticas públicas para este setor.

Teoria e Evidência Econômica - a. 26, n. 55, p. 297-310, jul./dez. 2020 


\section{Referencial teórico}

A história do queijo colonial inicia com a chegada dos imigrantes europeus ao Brasil, principalmente os italianos, no final do século XIX. Os registros sobre a comercialização desse queijo são escassos, provavelmente devido ao fato de que a bovinocultura de leite era incipiente e o queijo era um alimento produzido para 0 consumo das famílias, somente o excedente era utilizado para trocas em armazéns locais. No entanto, a denominação "queijo colonial" surgiu tempos depois, provavelmente com o intuito de denominar o queijo produzido nas colônias de imigrantes, a partir do momento em que passou a ser comercializado nas cidades. Por muito tempo, o produto era chamado somente de queijo ou "formaio"1 (AMBROSINI et $a l ., 2020)$.

Acreditamos que o queijo colonial possa fazer parte de um nicho, oferta na qual os consumidores valorizam, além do sabor, variáveis simbólicas que ultrapassam a materialidade do queijo e fazem parte dos ritos alimentares na vida cotidiana e se relacionam com as memórias afetivas (CHALITA, 2012; GRUNERT, 2005). Esses consumidores fazem parte do "quality turn", uma mudança que vem ocorrendo na percepção a respeito dos alimentos, em que a qualidade, antes relacionada aos alimentos industrializados, padronizados e produzidos em grande escala, passa a ser relacionada aos alimentos artesanais, locais, produzidos em pequena escala, que são vistos como mais saudáveis e sustentáveis (GOODMAN, 2004; PONTE, 2016).

De acordo com essas novas propostas de valorização dos alimentos, a produção artesanal de queijos vem ganhando destaque no Brasil, em meio a discussões sobre adequação da legislação, segurança do alimento e preservação desse modo de fazer, gerando também embates entre os processos tradicionais e as inovações (CRUZ; MENASCHE, 2014).

$\mathrm{Na}$ perspectiva de valorização da produção artesanal de alimentos de origem animal, o Ministério da Agricultura, Pecuária e Abastecimento publicou em 2018 a Lei no 13.680 , conhecida como "Lei do Selo Arte", que permite a comercialização interestadual de produtos alimentícios produzidos de forma artesanal, com inspeção sanitária municipal ou estadual, identificados com o selo ARTE. Especificamente para a produção de queijos artesanais, houve a publicação da Lei no 13.860, em 2019, que dispõe sobre a elaboração e a comercialização de queijos artesanais. Essa legislação define queijo artesanal como aquele elaborado por métodos tradicionais, com vinculação e valorização territorial, regional ou cultural, 
conforme protocolo de elaboração específico estabelecido para cada tipo e variedade, com emprego de boas práticas agropecuárias e de fabricação, e traz orientações a respeito da fabricação de queijos com leite cru.

A partir dessas legislações, é possível verificar que estão sendo propostas alternativas para formalização e proteção a esses modos de fazer, pois esses alimentos, além de nutrir, representam a história e a cultura de uma região e de sua população (GONZÁLEZ-CÓRDOVA et al., 2016).

O que ocorre muitas vezes é a comercialização informal desses produtos, ou seja, o queijo é vendido sem que tenha sido inspecionado pelo serviço de inspeção sanitária oficial, além de não atender a legislação tributária/fiscal e ambiental. Nessas relações comerciais, critérios como confiança no produtor, tradição, prestígio e outros critérios de qualidade são compartilhados na região e explicam a existência desse comércio (CLIMENT-LÓPEZ et al., 2014; CRUZ; MENASCHE, 2014).

\section{Procedimentos metodológicos}

Para avaliação das propriedades, foi elaborado um questionário composto por 22 questões. As questões foram agrupadas em três blocos: perfil socioeconômico, perfil produtivo da propriedade e caracterização do queijo (BERNUÉS; HERRERO, 2008; GARCÍA; DORWARD; REHMAN, 2012). Este trabalho irá abordar os resultados referentes ao perfil socioeconômico dos produtores.

Para a definição do tamanho da amostra, utilizou-se os dados do Relatório Socioeconômico da Cadeia Produtiva do Leite no Rio Grande do Sul (RIES; BITTENCOURT, 2015). A população-alvo foi definida a partir da quantidade de queijo produzido $(\mathrm{kg})$ e do número de propriedades que realizam a atividade: 224 agroindústrias familiares formalizadas e 8.093 produtores que comercializam derivados lácteos de fabricação caseira. $\mathrm{O}$ método de amostragem foi por conglomerado, utilizando as sete mesorregiões do estado. A partir dessas definições, foi calculado o tamanho da amostra para uma população finita, com base na estimativa da proporção populacional (RYAN, 2013), com um nível de confiança de $90 \%$ e uma margem de erro de $15 \%$.

Foram amostradas 293 propriedades rurais, das quais 82 possuem agroindústria familiar formalizada (AG), possuindo registro no serviço de inspeção municipal, e 211 realizam a fabricação de queijo colonial para o consumo familiar ou 
venda informal, o que se denominou de fabricação caseira (FC). A distribuição das propriedades amostradas é apresentada na Figura 1.

Figura 1 - Propriedades amostradas na pesquisa

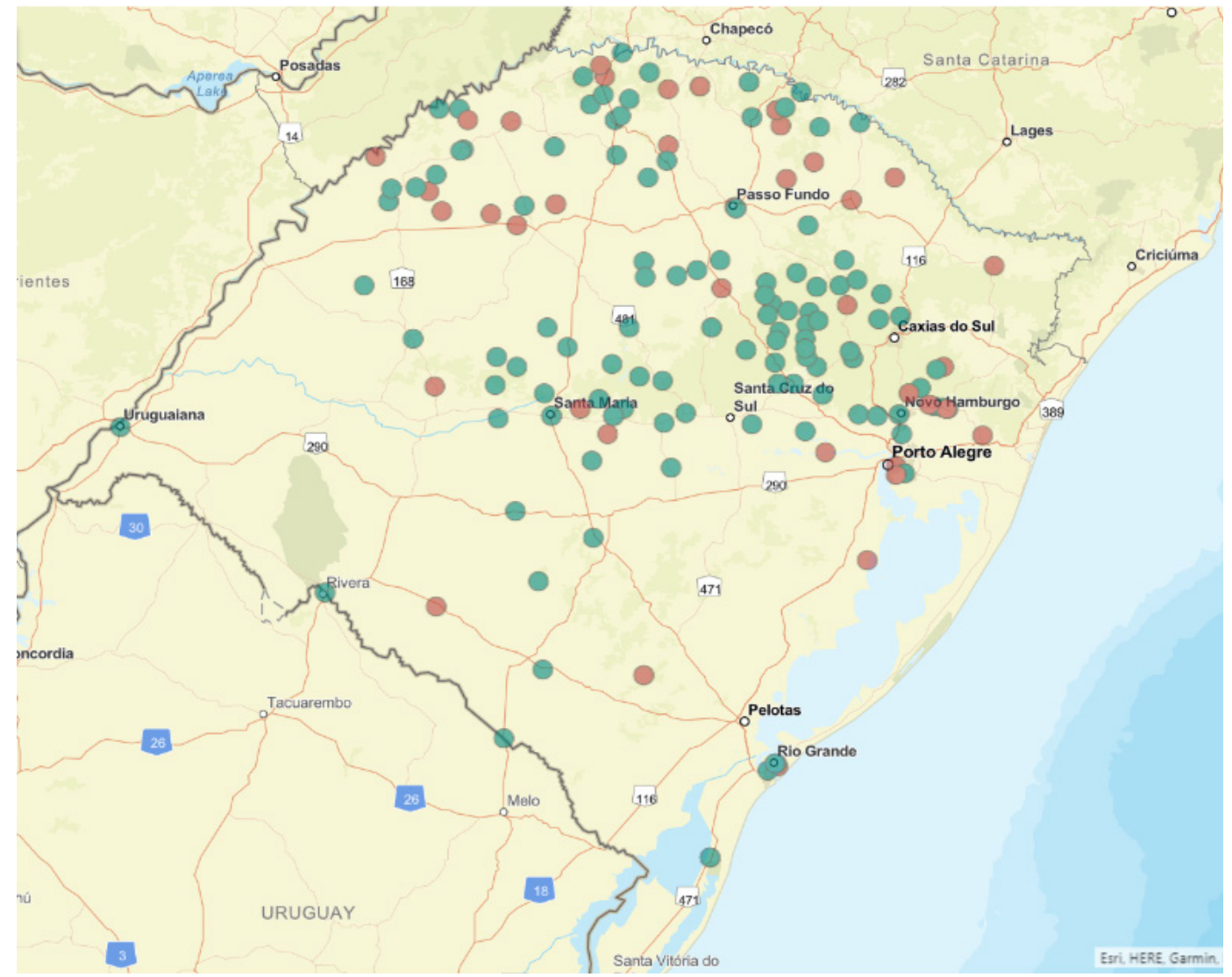

Fonte: elaboração dos autores.

A aplicação do questionário foi realizada pelos técnicos da Emater/RS-Ascar no período de junho de 2016 a dezembro de 2017. O questionário foi impresso pelos extensionistas e preenchido durante visita realizada nas propriedades. Juntamente com a aplicação do questionário, foram coletadas amostras do queijo produzido para realização de análises físico-químicas e microbiológicas. A escolha das propriedades a serem amostradas ficou a cargo do extensionista do município.

Após o recebimento dos questionários na gerência técnica estadual da Emater/RS-Ascar, os dados foram repassados para planilhas do Microsoft Excel, para 
serem posteriormente sistematizados e submetidos à análise descritiva pelo programa estatístico JMP (v.15).

\section{Resultados e discussão}

Em termos de perfil fundiário, os resultados demonstram que, nas propriedades onde há fabricação caseira de queijo, a área média é inferior em relação às propriedades com agroindústria familiar. As propriedades com agroindústria destinam áreas maiores para o cultivo de pastagens (perenes e anuais) e para o plantio de milho, destinado à silagem. As áreas médias encontradas foram superiores à média estadual, que foi estimada em 18,3 ha (EMATER/RS-ASCAR, 2019). Em relação à propriedade da terra, os percentuais são semelhantes para ambas as categorias, $45 \%$ FC e 41,1\% AG possuem terras próprias (Tabela 1). Sobre os residentes na propriedade, obteve-se uma média semelhante para a categoria fabricação caseira e agroindústria familiar em relação ao número de residentes e ao número de adultos, conforme pode ser observado na Tabela 1. As maiores diferenças são encontradas no número de jovens e empregados, sendo que as propriedades com agroindústria familiar possuem o dobro de jovens do que as propriedades com fabricação caseira. Essa informação vai ao encontro do que afirmam outros autores, mostrando que a agroindustrialização é uma oportunidade para a permanência dos jovens nas áreas rurais, através da agregação de valor à produção primária (FOGUESATTO et al., 2020; SULZBACHER; NEUMANN, 2014).

Tabela 1 - Caracterização dos residentes e da propriedade

\begin{tabular}{l|c|c|c|c}
\cline { 2 - 5 } & \multicolumn{2}{c|}{ Fabricação caseira } & \multicolumn{2}{c}{ Agroindústria familiar } \\
\hline \multirow{2}{*}{$\mathrm{N}^{\circ}$ de residentes na propriedade } & Média & Desvio padrão & Média & Desvio padrão \\
\cline { 2 - 5 } $\mathrm{N}^{\circ}$ de adultos & 3,5 & 1,4 & 4,0 & 1,8 \\
$\mathrm{~N}^{\circ}$ de jovens & 2,4 & 0,8 & 3,0 & 1,3 \\
$\mathrm{~N}^{\circ}$ de empregados & 1,3 & 0,5 & 2 & 1,4 \\
Área média (ha) & 1,8 & 1,6 & 2,6 & 2,8 \\
Área com pastagem (perene e anual) (ha) & 25,1 & 22,7 & 27,1 & 22,0 \\
Área de milho para silagem (ha) & 10,2 & 15,6 & 14,8 & 15,6 \\
Área própria (\%) & 3,1 & 3,6 & 6,7 & 7,8 \\
\hline
\end{tabular}

Fonte: Roldan et al. (2020). 
Os resultados mostram ainda que, nas propriedades onde se realiza a fabricação caseira do queijo colonial, a média de idade é superior em relação às propriedades onde há agroindústria (Tabela 2). O nível de escolaridade é inferior entre os produtores que fazem a fabricação caseira: $60 \%$ dos entrevistados têm apenas ensino fundamental incompleto, enquanto a média de entrevistados com ensino médio é de $34 \%$ na categoria de agroindústria familiar, que também tem mais que o dobro de produtores com ensino superior (8\%). A idade média superior na categoria de fabricação caseira pode explicar a escolaridade inferior verificada, devido às dificuldades que essas pessoas enfrentaram para ter acesso à educação quando crianças, e também à informalidade da atividade de produção do queijo, visto que são pessoas mais velhas, próximas à aposentadoria, que não desejam fazer investimentos e iniciar uma nova atividade.

Tabela 2 - Perfil dos produtores de queijo entrevistados

\begin{tabular}{l|c|c|c|c}
\cline { 2 - 5 } & \multicolumn{2}{c|}{ Fabricação caseira } & \multicolumn{2}{c}{ Agroindústria familiar } \\
\cline { 2 - 5 } & Média & Desvio padrão & Média & Desvio padrão \\
\hline Idade média (anos) & 51,3 & 10,4 & 45,2 & 11,5 \\
Tempo de fabricação de queijo colonial (anos) & 21,8 & 16,4 & 14,4 & 12,6 \\
Ensino fundamental incompleto (\%) & 60 & - & 33 & - \\
Ensino fundamental completo (\%) & 17 & - & 16 & - \\
Ensino médio (\%) & 16 & - & 34 & - \\
Ensino superior (\%) & 3 & - & 8 & - \\
\hline
\end{tabular}

Fonte: Roldan et al. (2020).

García, Dorward e Rehman (2012), em pesquisa com pequenos produtores de leite no México, verificaram que quanto maiores a idade e a experiência do agricultor, menor é a sua escolaridade. Dados semelhantes foram encontrados por Cruz et al. (2020) em pesquisa com produtores de queijos artesanais da Ilha de Marajó (PA), onde há o predomínio de idade elevada e baixa escolaridade entre os produtores.

Os dados revelam também que os produtores de queijo de fabricação caseira produzem queijo colonial há mais tempo, média de 21,8 anos, enquanto na agroindústria familiar a média é de 14,4 anos. Esses valores podem estar relacionados a uma maior idade dos entrevistados de FC, juntamente ao fato de que o queijo 
colonial era historicamente produzido para consumo familiar, sendo o hábito do preparo e consumo repassado às gerações seguintes (AMBROSINI et al., 2020).

A média de tempo de produção do queijo pode ser considerada alta e está de acordo com o encontrado por Seixas et al. (2014) em pesquisa com produtores de queijos tradicionais na Ilha de Marajó. Segundo seus resultados, $80 \%$ dos produtores de queijo tipo creme e $100 \%$ dos produtores de queijo tipo manteiga possuíam mais de 10 anos de experiência no processamento.

Em ambas as categorias pesquisadas, a origem italiana das famílias predominou, conforme mostrado na Figura 1. Esse resultado corrobora o encontrado por Ambrosini et al. (2020), que relaciona a origem e a maior produção do queijo colonial entre imigrantes italianos, que produziam o "formaio", como assim o denominavam, para consumo familiar e venda ou troca do excedente nos armazéns locais.

Figura 1 - Origem das famílias produtoras de queijo colonial

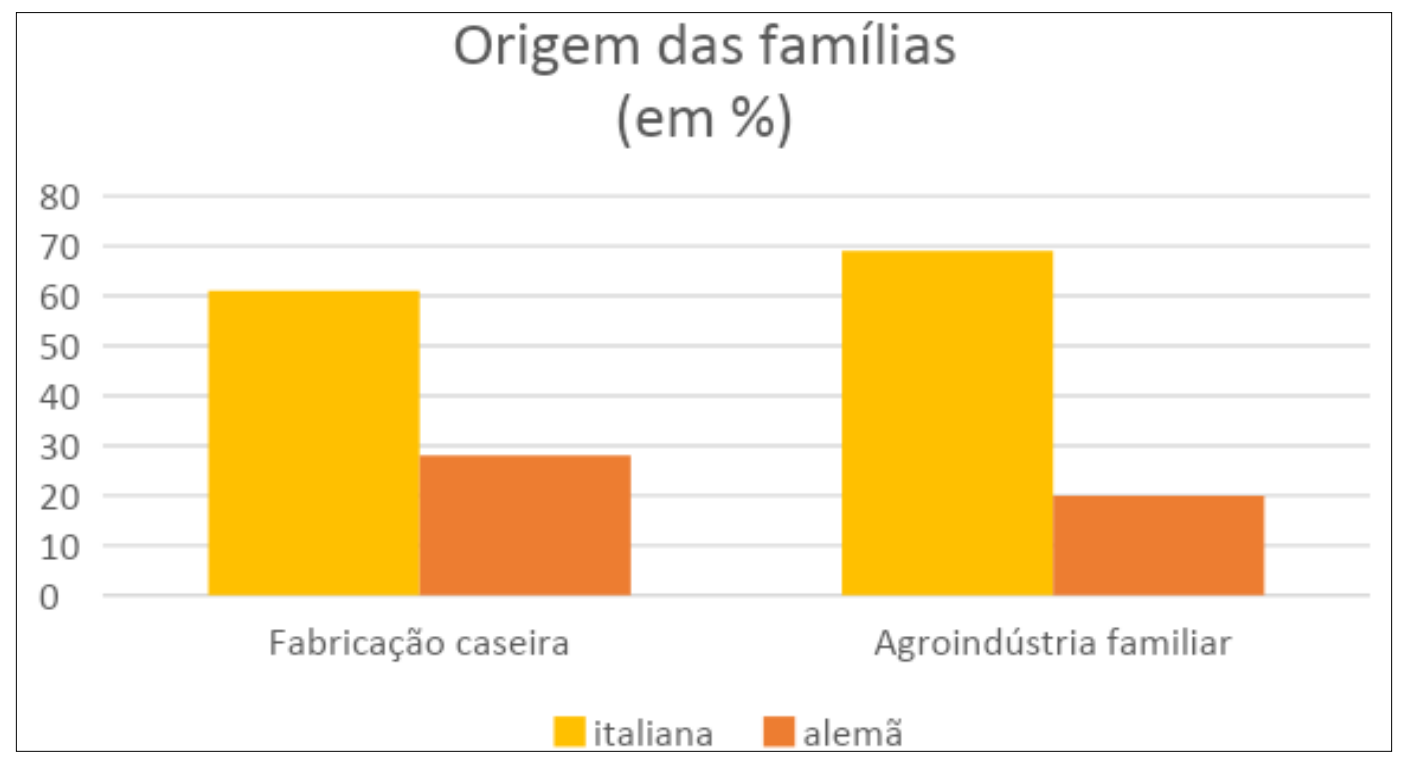

Fonte: Roldan et al. (2020).

Em relação ao perfil produtivo, observou-se que as atividades de bovinocultura de leite, produção de grãos e frutiolericultura são as principais desenvolvidas em ambas as categorias pesquisadas, com percentuais semelhantes, conforme pode ser observado na Figura 2. A exceção foi frutiolericultura, que apresenta percentuais de $38 \%$ nas propriedades de fabricação caseira e $17 \%$ para a agroindústria familiar. 
Figura 2 - Atividades desenvolvidas nas propriedades

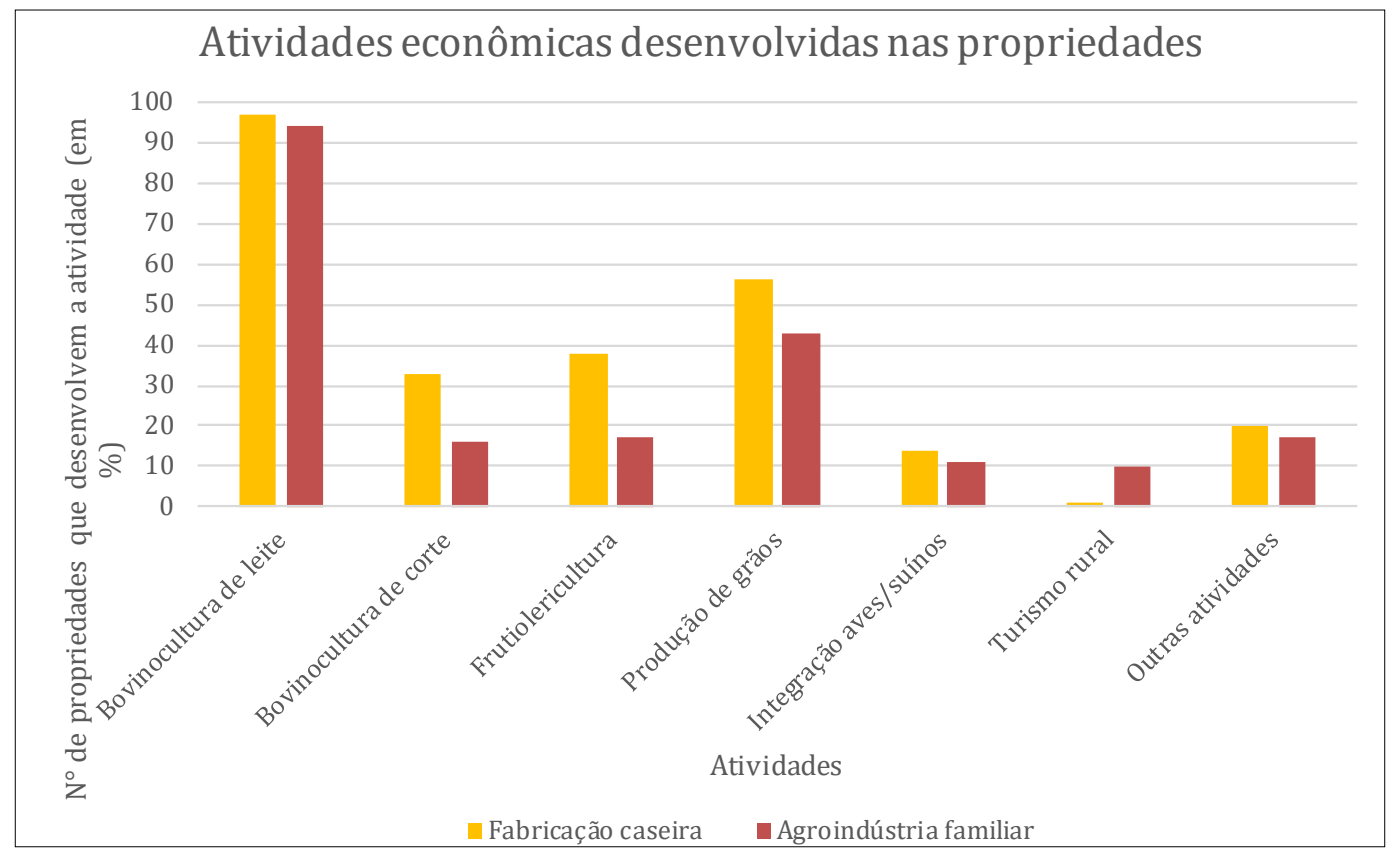

Fonte: Roldan et al. (2020)

Foi verificado que a atividade de turismo rural é desenvolvida em $10 \%$ das propriedades que possuem agroindústria familiar. Esse resultado está de acordo com o verificado por outros autores, que pontuam a relação existente entre o desenvolvimento da agroindustrialização de produtos da propriedade com o turismo rural (CIOLAC et al., 2019; KIM et al., 2019).

Os produtores foram questionados sobre os canais de comercialização utilizados para a venda do queijo colonial. Os produtores FC também responderam a esta questão, visto que é sabido que parte deles realiza a venda informal do produto, ou seja, sem atender às legislações pertinentes. Grande parte dos produtores FC afirmaram realizar a venda diretamente na propriedade (40\%) e venda direta ao consumidor, por meio da entrega de encomendas (29\%), caracterizando um circuito curto de comercialização. Esses resultados mostram que a venda desse tipo de produto está relacionada às relações de confiança estabelecidas entre o produtor e o consumidor, em que a crença dos consumidores de que os produtos têm as qualidades anunciadas ou foram preparados de acordo com os métodos especificados desempenha um papel fundamental (CLIMENT-LÓPEZ et al., 2014; CRUZ et al., 2020). 
O consumidor cria e estabelece seus próprios requisitos de qualidade, que muitas vezes não estão somente relacionados a características intrínsecas do alimento, mas também ao interesse pela origem geográfica ou procedência dos alimentos, pelo turismo, através de sensibilidades estéticas, aestésicas e afetivas. Esses requisitos podem determinar a escolha e o consumo do alimento (CHALITA, 2012; GRUNERT, 2005).

Resultados semelhantes foram encontrados para a comercialização de queijos artesanais informais da Ilha do Marajó, onde 60\% dos casos analisados realizavam a venda diretamente ao consumidor (SEIXAS et al., 2014). Ao contrário do relatado para o queijo artesanal da região de Alagoa (MG), onde a maioria dos produtores vende o queijo para intermediários, que compram grandes remessas do produto fresco e realizam a maturação nos locais de venda (SANTOS et al., 2018).

Já a venda dos queijos da agroindústria familiar acontece principalmente para intermediários: $24 \%$ para varejistas na cidade onde o estabelecimento está situado e 5\% para intermediários em geral. Os demais canais de comercialização também são utilizados em proporção semelhante, entre venda diretamente na propriedade, venda em feiras e venda direta ao consumidor, conforme apresentado na Tabela 3.

Tabela 3 - Canais de comercialização do queijo colonial

\begin{tabular}{l|c|c}
\cline { 2 - 3 } & Fabricação caseira & Agroindústria familiar \\
\hline Direto na propriedade (\%) & 40 & 13 \\
Em feiras (\%) & 11 & 15 \\
Para varejistas (\%) & 3 & 7 \\
Venda direta ao consumidor (\%) & 29 & 13 \\
Venda para intermediários (\%) & 4 & 5 \\
Venda para varejistas na cidade (\%) & 3 & 24 \\
\hline
\end{tabular}

Fonte: Roldan et al. (2020).

Em relação à contribuição da venda do queijo na renda total da propriedade, para a categoria FC, a venda do queijo contribui com $24 \%$, mostrando que essa venda tem um papel complementar às demais atividades desenvolvidas. Resultados semelhantes foram encontrados por Seixas et al. (2014), em pesquisa realizada com produtores de queijo artesanal na Ilha do Marajó, onde foi verificado que, para $80 \%$ dos entrevistados, a fabricação do queijo não era a principal fonte de renda. 
Já nas propriedades com agroindústria familiar, a venda do queijo contribui com 55\% da renda total, ou seja, a agroindustrialização, que também era vista como complementar às demais atividades, como a lavoura e a pecuária, tem um papel muito importante, sendo responsável por mais da metade da renda. Isso demonstra a relevância da atividade de agroindustrialização como promotora do desenvolvimento rural, por meio da agregação de valor e através da geração de trabalho e renda (CRUZ et al., 2020; SEIXAS et al., 2014).

\section{Conclusão}

Por meio da análise do perfil socioeconômico dos produtores e da atividade de produção de queijo colonial, pôde-se verificar que a idade avançada dos produtores, a longa experiência no processamento, a origem da atividade nos imigrantes italianos, bem como circuitos curtos de comercialização e as relações de confiança entre produtores e consumidores, caracterizam a atividade de produção de queijo colonial como tradicional.

Tendo em vista o número de pessoas envolvidas e a produção estimada de queijo colonial, é importante o estabelecimento de políticas públicas específicas para este setor, que contemplem financiamento e adaptação de legislações para o incentivo à formalização, com capacitações para os produtores, incluindo boas práticas agropecuárias e de fabricação. Além disso, a valorização do produto e do modo artesanal de processamento deve ser uma medida para fomentar o processamento do queijo colonial como forma de geração de renda, alternativa para os jovens e o desenvolvimento rural.

\section{Declaração de conflito de interesses}

Não temos conflito de interesse a declarar.

\section{Agradecimentos}

Agradecemos aos produtores de queijo colonial e aos extensionistas rurais da Emater/RS-Ascar, que foram parte fundamental desta pesquisa. 


\title{
Socioeconomic profile of colonial cheese producers and the importance of artisanal production
}

\begin{abstract}
Colonial cheese is very popular with consumers, being produced basically with three ingredients: milk, rennet and salt. Its production is carried out in the family environment, for domestic consumption or for informal sale and by small, medium and large companies. Due to the economic, social and cultural importance that this product has, this study sought to analyze the socioeconomic profile of colonial cheese producers in the state of Rio Grande do Sul. It was possible to verify that the advanced age of the producers, the experience, the origin of the activity in the Italian immigrants, as well as short circuits of commercialization and the relations of trust between producers and consumers characterize the colonial cheese production activity as traditional.
\end{abstract}

Keywords: family agribusiness; adding value; rural development.

\section{Perfil socioeconómico de los productores de queso colonial gaucho y la importancia de la producción artesanal}

\section{Resumen}

El queso colonial es muy apreciado por los consumidores, y es elaborado básicamente con tres ingredientes: leche, cuajo y sal. Su producción se realiza en el ámbito familiar, para consumo interno o para venta informal y por pequeñas, medianas y grandes empresas. Debido a la importancia económica, social y cultural que tiene este producto, este estudio buscó analizar el perfil socioeconómico de los productores de queso colonial en el estado de Rio Grande do Sul. Se pudo constatar que la edad avanzada de los productores, la experiencia en la producción, el origen de la actividad en los inmigrantes italianos, así como los cortos canales de comercialización y las relaciones de confianza entre productores y consumidores caracterizan la actividad de producir queso colonial como tradicional.

Palabras claves: agroindustria familiar; valor agregado; desarrollo rural.

\section{Nota}

1 Formaio: denominação de queijo no dialeto vêneto, falado pelos imigrantes italianos. 


\section{Referências}

AMBROSINI, L. B. et al. História do queijo colonial do Rio Grande do Sul: das cozinhas para o mercado. Revista História: Questões e Debates. 14 maio 2020. No prelo.

BERNUÉS, A.; HERRERO, M. Farm intensification and drivers of technology adoption in mixed dairy-crop systems in Santa Cruz, Bolivia. Spanish Journal of Agricultural Research, v. 6, n. 2, p. 279-293, 2008.

BRASIL. Lei $\mathrm{n}^{\circ} 13.680$, de 14 de junho de 2018. Altera a Lei ${ }^{\circ} 1.283$, de 18 de dezembro de 1950, para dispor sobre o processo de fiscalização de produtos alimentícios de origem animal produzidos de forma artesanal. Diário Oficial da União, Brasília, DF, 15 de junho de 2018.

BRASIL. Lei ${ }^{\circ} 13.860$, de 18 de julho de 2019. Dispõe sobre a elaboração e a comercialização de queijos artesanais e dá outras providências. Diário Oficial da União, Brasília, DF, 19 de julho de 2019.

CHALITA, M. A. N. O consumo de queijo como referência para a análise do mercado de qualidade do produto. Revista de Economia e Sociologia Rural, v. 50, n. 3, p. 545-562, 2012.

CIOLAC, R. et al. Agritourism-A sustainable development factor for improving the "health" of rural settlements. Case study Apuseni Mountains area. Sustainability, Switzerland, v. 11, n. 5, 2019.

CLIMENT-LÓPEZ, E. et al. Measuring quality conventions in the food industry: Applications to the wine sector in Spain. Geoforum, v. 56, p. 148-160, 2014.

CRUZ, B. E. V. da et al. Redes sociais e preservação dos modos de produção de queijos artesanais da Ilha do Marajó, PA. Redes, v. 25, n. 2, p. 506-526, 2020.

CRUZ, F. T. da; MENASCHE, R. O debate em torno de queijos feitos de leite cru: entre aspectos normativos e a valorização da produção tradicional. Vigilância Sanitária em Debate, v. 2, n. 4, p. 34-42, 2014.

EMATER/RS-ASCAR. Relatório socioeconômico da cadeia produtiva do leite no Rio Grande do Sul: 2019. [S.l.: s.n.], 2019.

ESPINOZA-ORTEGA, A. et al. Small-scale dairy farming in the highlands of central Mexico: technical, economic and social aspects and their impact on poverty. Experimental Agriculture, v. 43, n. 2, p. 241-256, 2007.

FLATEN, O. Alternative rates of structural change in Norwegian dairy farming: Impacts on costs of production and rural employment. Journal of Rural Studies, v. 18, n. 4, p. 429-441, 2002.

FOGUESATTO, C. R. et al. Will I have a potential successor? Factors influencing family farming succession in Brazil. Land Use Policy, v. 97, n. February 2019, p. 104643, 2020.

GARCÍA, C. G. M.; DORWARD, P.; REHMAN, T. Farm and socio-economic characteristics of smallholder milk producers and their influence on technology adoption in Central Mexico. Tropical Animal Health and Production, v. 44, n. 6, p. 1199-1211, 2012.

GONZÁLEZ-CÓRDOVA, A. F. et al. Invited review: Artisanal Mexican cheeses. Journal of Dairy Science, v. 99, n. 5, p. 3250-3262, 2016.

GOODMAN, D. Rural Europe Redux ? Reflections on Alternative Agro-Food Networks and Paradigm Change. Sociologia Ruralis, v. 44, n. 1, 2004. 
GRUNERT, K. G. Food quality and safety: consumer perception and demand. European Review of Agricultural Economics, v. 32, n. 3, p. 369-391, 2005.

KIM, S. et al. The effect of agritourism experience on consumers' future food purchase patterns. Tourism Management, v. 70, n. August 2018, p. 144-152, 2019.

PONTE, S. Convention theory in the Anglophone agro-food literature: Past, present and future. Journal of Rural Studies, v. 44, p. 12-23, 2016.

RIES, J. E.; BITTENCOURT, S. L. J. Relatório socioeconômico da cadeia produtiva do leite no Rio Grande do Sul. Porto Alegre: Emater/RS-Ascar, 2015.

RYAN, T. P. Sample Size Determination and Power. [S.l.]: Wiley Series in Probability and Statistics, 2013.

SANTOS, G. M. dos et al. Perfil da produção artesanal na região de montanha em Alagoa, no sul de Minas Gerais. Revista de Geografia, v. 8, n. 1, p. 01-11, 2018.

SEIXAS, V. N. C. et al. Socioeconomic diagnosis of cheese producers of Marajó, state of Pará, Brazil. Revista do Instituto de Laticínios Cândido Tostes, v. 69, n. 5, p. 309-321, 2014.

SILVEIRA, P. R. C. da; TREVISAN, A. P. A produção e comercialização de queijos coloniais: dinâmicas de validação social da qualidade. In: CONGRESSO DA SOCIEDADE BRASILEIRA DE ECONOMIA, ADMINISTRAÇÃO E SOCIOLOGIA RURAL, 45. Anais [...]. Londrina: 2007.

SULZBACHER, A. W.; NEUMANN, P. S. O social e suas dimensões em agroindústrias familiares rurais. Extensão Rural, v. 21, n. 3, p. 93-120, 2014.

TAVARES, A. B. et al. Artisanal cheese produced in the south of Rio Grande do Sul: Physicalchemical, microbiological assessment and susceptibility of antimicrobials from Staphylococcus coagulase positive isolates. Ciencia Animal Brasileira, v. 20, p. 1-10, 2019.

ZUMBO, A. et al. Ripening-induced changes in microbial groups of artisanal Sicilian goats' milk cheese. Italian Journal of Animal Science, v. 8, n. suppl. 2, p. 450-452, 2009. 